\title{
Gary Victor, L’Escalier de mes désillusions
}

\section{Elena Fermi}

\section{OpenEdition}

\section{Journals}

\section{Édition électronique}

URL : http://journals.openedition.org/studifrancesi/663

DOI : 10.4000/studifrancesi.663

ISSN : 2427-5856

\section{Éditeur}

Rosenberg \& Sellier

\section{Édition imprimée}

Date de publication : 1 avril 2015

Pagination : 209-210

ISSN : 0039-2944

\section{Référence électronique}

Elena Fermi, « Gary Victor, L'Escalier de mes désillusions », Studi Francesi [En ligne], 175 (LIX | I) | 2015, mis en ligne le 01 avril 2015, consulté le 18 septembre 2020. URL : http://journals.openedition.org/ studifrancesi/663 ; DOI : https://doi.org/10.4000/studifrancesi.663

\section{Ce document a été généré automatiquement le 18 septembre 2020}

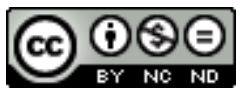

Studi Francesi è distribuita con Licenza Creative Commons Attribuzione - Non commerciale - Non opere derivate 4.0 Internazionale. 


\title{
Gary Victor, L'Escalier de mes désillusions
}

\author{
Elena Fermi
}

\section{RÉFÉRENCE}

GARY VICTOR, L'Escalier de mes désillusions, Paris, Philippe Rey, 2014, pp. 192.

Dans son dernier roman, Gary Victor reprend et développe les sujets qu'il avait abordés il y a deux ans dans Maudite éducation. Dans ce roman en partie autobiographique, l'auteur avait raconté l'adolescence du jeune Carl Vausier dans les années soixante-dix, lorsqu'Haïti était sous l'emprise de la dictature duvaliériste. Hanté par ses fantasmes, tiraillé entre la crainte d'un père rigide et le désir d'explorer le nouveau continent de la sexualité, Carl y allait jusqu'au bout de ses expériences: l'amour physique avec les prostituées des bas-fonds de Port-au-Prince, la passion par correspondance pour la jeune Cœur qui Saigne et le fiasco de leur première rencontre. Puis l'obsession de vouloir rattraper les erreurs du passé et de réécrire sa propre histoire, les rendez-vous manqués avec son père, les non-dits, les incompréhensions. Une histoire personnelle qui se construit pendant que l'histoire de son pays voit la dictature redoubler de violence et de brutalité.

2 Avec L'Escalier de mes désillusions, Victor bâtit un roman où il joue savamment sur les deux plans de la mémoire d'un passé resté en suspens et de l'actualité tragique du séisme qui a frappé Haïti en 2010, dans la tentative - peut-on penser - de «boucler la boucle». Carl Vausier, le protagoniste de Maudite éducation, y réapparaît; il a grandi, est devenu un homme adulte et un écrivain affirmé mais il n'est toujours pas arrivé au bout de son questionnement sur la vie, l'amour, l'écriture, la relation avec l'autre. Le roman s'ouvre sur les instants qui suivent immédiatement la première secousse du tremblement de terre. Échappé à la mort «par un caprice du hasard» dans une ville complètement ravagée, Carl Vausier se précipite alors auprès de sa belle-mère, Man Hernande, espérant y retrouver ou y avoir des nouvelles de son ex femme, Jézabel, et de 
sa fille, Hannah. Ne trouvant que sa belle-mère, il reste là, démuni, avec elle, en silence, l'angoisse chevillée au corps, attendant un signe de vie, au milieu du chaos de son pays déjà tellement usé par la pauvreté et par la répression contre laquelle il s'élève au fil du roman. L'immobilité forcée du corps de Carl qui, secoué par le choc et par la peur d'apprendre une nouvelle fatale, reste serré à Man Hernande dans une attente interminable, laisse cependant libre cours à ses pensées. Les brèches que le séisme ouvre dans la terre d'Haïti percent également l'esprit de Carl qui se livre à une introspection qui libère des sentiments trop longtemps tus, réveille des souvenirs puissants et cuisants. Comme si les remous de la terre avaient aussi tout remué en lui, comme si la colère de la nature, le fait d'être l'un des survivants et la crainte d'avoir perdu les deux êtres qu'il aime le plus au monde l'avaient soudain réveillé, il entre dans une sorte de délire post apocalyptique. Il revient sur son passé, ses histoires sentimentales, son mariage, il entreprend une réflexion et essaie de comprendre l'origine de ses échecs mais aussi de ses succès. Réapparaissent alors des personnages de Maudite éducation - Cœur qui Saigne, Gaston Paisible, le poète qui avait initié Carl à l'écriture - le caporal Dieusoitloué (protagoniste des romans de la série noire vaudou) y fait également une apparition mais la scène est essentiellement occupée par la figure de son père, dont Vausier/Victor évoque les funérailles tout au long de la première partie du roman. Affleurent alors les regrets d'un homme, ainsi que d'une mère, de ne pas avoir mieux dévoilé des sentiments ou des éléments importants tant qu'on le pouvait, la culpabilité d'avoir dissimulé des secrets, pourtant fondamentaux pour l'épanouissement des personnes que l'on aime. Dans un style fébrile, troublant, Gary Victor monte les marches de cet escalier idéal qui fait le titre de son roman et, ce faisant, parcourt peu à peu les désillusions de son existence. Il entraîne ses lecteurs dans des secrets de famille ou personnels, dans la folie de certains actes et le poids que l'on doit ensuite porter à vie. Le tout s'appuyant sur un dispositif romanesque imparable. Jouant sur le côté autobiographique, faisant de son protagoniste un écrivain affirmé, il met constamment en abyme l'écriture qui y devient une modalité d'être au monde. Ainsi la narration est ponctuée, dès ses toutes premières pages, par une réflexion sur la pulsion à raconter, à «noircir des pages» pour donner plus de consistance, mettre en relief les souvenirs enfouis. Les temporalités s'entrechoquent tout au long du roman; le lecteur s'égare entre les évocations du passé, les réflexions psychologiques et l'actualité de l'attente. Victor y conjugue avec expérience l'esprit cartésien et l'occultisme vaudou, seul moyen que Carl Vausier trouve, en fin de compte et malgré son mépris, pour saisir en profondeur l'environnement fantasmatique au milieu duquel il vit. Les motifs ésotériques foisonnent dans le roman et constituent une interprétation poétique du réel qui n'est pas sans rappeler le réalisme magique de Gabriel Garcia Marquez (d'ailleurs l'un des écrivains de référence de Victor). L'histoire d'Haïti - les années de résistance à la dictature, la crainte des tontons macoutes, puis les difficultés de la transition démocratique - est aussi abordée dans ce roman où elle forme une sorte de toile de fonds.

3 Tout comme dans Maudite éducation où il s'était mis à nu, dans L'Escalier de mes désillusions, Victor essaie de tirer un bilan «à chaud». A-t-il enfin bouclé sa boucle? Y at-il vraiment une boucle à boucler? «Je sais que j'aurai peut-être à monter d'autres marches sur l'escalier de mes désillusions. La frêle beauté du présent est souvent le meilleur bouclier contre les jets assassins du destin» (p. 190) - dit-il en clôture du roman. Les fractures dans la terre ont rouvert de profondes et étroites fissures dans 
l'homme et ont peut-être fait parcourir à sa conscience un petit bout de chemin dans l'exploration de son intériorité. 